\title{
Pharmacokinetics of isoniazid with or without ofloxacin
}

\author{
Sinyeofori A. Brown, Ndidiamaka A. Ezejiofor, *Orish E. Orisakwe \\ Faculty of Pharmaceutical Sciences, University of Port Harcourt, Rivers State, Nigeria
}

\begin{abstract}
Objective of the resent study was to determine the effect of ofloxacin (OXC) on the pharmacokinetics of isoniazid (INH). Five healthy volunteers aged $18-39$ years participated in this study after an informed consent. The study was carried out in two phases with an interval of one-week drug wash out period in between phases. In phase one (INH alone), each subject received $300 \mathrm{mg}$ of isoniazid (INH) with $350 \mathrm{ml}$ of water after an overnight fast. The subjects were made to fast 2 hours post drug. In phase two (INH + OXC), each subject was administered with 300mg of INH in combination with $200 \mathrm{mg}$ of OXC observing all the protocol in phase one. The concentration of INH in plasma, saliva and urine of the subjects at predetermined time intervals were measured spectrophotometrically in the two phases over a period of 0 - 48 hours. Various pharmacokinetics parameters were calculated. From the study it is evident that Ofloxacin (OXC) increased the rate and extent of absorption of isoniazid. The absorption half-life ( $\left.\mathrm{t}_{1 / 2 a}\right)$ and the maximum concentration and absorption time $\left(\mathrm{C}_{\max }, \mathrm{T}_{\max }\right)$ of isoniazid $(\mathrm{INH})$ were increased in the presence of OXC. The urinary excretion of isoniazid was also increased by ofloxacin. The salivary concentration of isoniazid was less than the corresponding plasma drug concentrations, a pattern also found in similar studies. Thus it can be concluded that Ofloxacin increases absorption kinetics and urinary excretion of Isoniazid.
\end{abstract}

Key Words: Antimycobacterial drugs, salivary, plasma, flouroquinolones, mycobacterial leprae, rifampicin.

\section{INTRODUCTION}

Leprosy and tuberculosis, continue to be public health concern in many countries around the world. World Health Organization (WHO, 2010a) estimated that there were over 244000 reported cases globally in 2009. Due to the resistance of most strains of $M$. leprosy and $M$. tuberculosis, the treatment of leprosy has changed in the past three decades. Dapsone monotherapy was replaced by multidrug therapy (with dapsone, rifampicin and clofazimine) in 1982 (WHO, 1982; Gautam, 2009). Since its introduction, multidrug therapy has been an important tool in leprosy elimination; not only has it helped to reduce the duration of treatment but it has also been useful in addressing problems related to resistance to dapsone and relapses (Gautam, 2009; Visschedijk et al., 2000; Meima et al., 2004). Thus, there has been a renewed effort to find

\footnotetext{
*Corresponding Author:

Prof Orish Ebere Orisakwe

Faculty of Pharmaceutical Sciences

University of Port Harcourt

Rivers State, Nigeria

E-mail: eorish@aol.com

Contact No.: 08068533281
}

newer regimens that may shorten the duration of therapy and improve compliance while simultaneously maintaining or improving the therapeutic advantages of previous regimens (Sehgal et al., 2008; Maninder et al., 2011).

Isoniazid (INH) has remained one of the first line drugs for the treatment of tuberculosis and leprosy since its discovery. It is highly effective against mycobacteria for which its minimal tuberculostatic concentration is $0.025-0.5 \mathrm{mcg} / \mathrm{ml}$ whereas concentrations of over $500 \mathrm{mcg} / \mathrm{ml}$ are required to inhibit the growth of other microorganisms (Dorthe et al., 1995).

Fluoroquinolones represent a class of antimicrobials which has gained popularity because of their very impressive pharmacokinetics properties, efficacy, convenient oral dosage schedule, broad-spectrum anti-microbial activity and low incidence of adverse reactions (Goel et al., 1998; Walker et al., 1991; Wolfson and Hooper, 1991a; Kumar and Gurumurthy, 2004, EMEA/CVMP/SAGAM, 2004; O'Brien et al., 2012). Ofloxacin, is a synthetic analogue of nalidixic acid which inhibit the bacterial enzyme 
DNA gyrase that is responsible for the control of the super coiling of the bacterial DNA; ofloxacin is also responsible for the continuous introduction of negative super coils into DNA (Diver, 1998; WHO, 1998a; Guay, 1992a). It precipitates seizure in epileptics and also causes arthropathy in young (WHO, 1998b). Drug combination therapy including ofloxacin and isoniazid have been employed in the management of mycobacterial infections.

The determination of drug concentrations in the saliva and urine has gained widespread acceptance in a variety of settings (Drobitch and Svensson, 1992). The estimation of drugs in the saliva and urine has been employed for therapeutic drug monitoring, effectiveness of the excretory organs and for calculation of pharmacokinetic variables (Mucklow, 1982). The rational use of such determinations can provide knowledge of patient-specific pharmacokinetic parameters leading to improved therapy (Spectar et al., 1988). Saliva and urine can serve as an alternative body fluid for pharmacokinetic investigations. It can be collected with minimal patient discomfort and can be easily obtained on multiple occasions. It is particularly suitable for investigations in geriatrics and pediatrics. Pharmacokinetic studies have shown that ofloxacin penetrates into saliva and its concentration correlates well with serum levels (Guay, 1992b).

The present study was undertaken to evaluate the pharmacokinetics of isoniazid (INH) in saliva, plasma and urine when administered alone or in combination with other antimycobacterial drugs ofloxacin (OXC). We have also attempted to calculate the saliva-plasma ratio of INH.

\section{MATERIALS AND METHODS}

\section{Study participant}

Five healthy subjects aged between 18 and 39 years and weight range between $50-83 \mathrm{Kg}$ participated in the study after an informed consent. The subjects were assessed to be healthy on the basis of medical history, hepatic and renal function tests. None of the subjects was taking any medication one week before or during the study for any ailment and were nonalcoholics. The study protocol was approved by the Institutional Ethics Committee and written informed consent was obtained from all the volunteers.

\section{Study design}

In phase one (INH alone), each subject initiated the study after an overnight fast. One $300 \mathrm{mg}$ tablet (usual adult dose) of INH was administered orally with about $350 \mathrm{ml}$ of water. Food was restricted for 2 hours after commencement. Blood and saliva samples were collected at $0 \mathrm{hr}$ (i.e. just before taken INH) then half hourly until 8th hour then at 12th and 24th hour. Urine samples were also collected at zero hour, then hourly until the 8 th hour, then at 12th hour, 24th hour and finally at 48th hour. The same procedure was followed for phase two (INH + OXC) after a one-week drug wash-out period and the drug administered (orally) to the subject was $300 \mathrm{mg}$ of INH and 200mg film coated OXC tablets and all the samples collected as in phase one (INH alone).

\section{Sample collection and handling}

The total volume of urine voided at each occasion was recorded and $10 \mathrm{ml}$ of the urine was withdrawn and placed in a test tube. The $\mathrm{pH}$ of the urine samples was estimated using $\mathrm{pH}$ meter. One millilitre of toluene was added to the urine and stored frozen at $-20^{\circ} \mathrm{C}$ until analysis. About $3 \mathrm{ml}$ of saliva was collected at the predetermined time intervals and the $\mathrm{pH}$ of the samples was estimated as stated for the urine samples. The test tubes of the saliva were stored frozen at $-20^{\circ} \mathrm{C}$ until analyzed.

Blood samples were collected through indwelling butterfly (scalp vein) needles kept patent with heparinized normal saline. The heparinized saline was withdrawn with a syringe prior to each blood sample collection. About $4 \mathrm{ml}$ of blood sample was collected and placed in EDTA containing test tubes pending the separation of the plasma. Blood samples were centrifuged and only the plasma collected and stored frozen at $-20^{\circ} \mathrm{C}$ until analyzed.

\section{Sample analysis}

The spectrophotometric method of Bjornesjo and Jarnuff (Bjornosjo and Jarnuff, 1967) was used with slight modification in the assay of INH in saliva and urine samples, while plasma INH concentration was analyzed using the Ehrlich's reagent. About $1 \mathrm{ml}$ of $2 \mathrm{M}$ acetic acid and $1 \mathrm{ml}$ of chromogenic reagents freshly prepared from equal volume of $2 \%$ sodium nitroprusside and $4 \mathrm{M} \mathrm{NaOH}$ was added to $2 \mathrm{ml}$ of urine. The mixture was vortexed and absorbance 
Table 1. Plasma and saliva INH Pharmacokinetic Parameters with or without OXC.

\begin{tabular}{|c|c|c|}
\hline $\begin{array}{l}\text { Parameters } \\
\text { (units) }\end{array}$ & Without OXC & With OXC \\
\hline $\mathrm{C}_{\max }(\mathrm{mcg} / \mathrm{ml})$ & $\begin{array}{l}4.50 \pm 0.20 \\
(1.70 \pm 0.10)^{*}\end{array}$ & $\begin{array}{l}4.70 \pm 0.20 \\
(1.90 \pm 0.10)^{*}\end{array}$ \\
\hline $\mathrm{T}_{\max }(\mathrm{hr})$ & $\begin{array}{l}1.50 \pm 0.29 \\
(3.00 \pm 0.00)^{*}\end{array}$ & $\begin{array}{l}2.00 \pm 0.29 \\
(3.00 \pm 0.00)^{*}\end{array}$ \\
\hline $\begin{array}{l}\text { AUC } 0-24 h \\
(\mathrm{mcg} / \mathrm{ml} / \mathrm{hr})\end{array}$ & $\begin{array}{l}65.50 \pm 6.82 \\
(8.96 \pm 0.37)^{*}\end{array}$ & $\begin{array}{l}59.60 \pm 6.82 \\
(9.35 \pm 0.37)^{*}\end{array}$ \\
\hline $\begin{array}{l}\text { AUC } 0 \text {-inf } \\
(\mathrm{mcg} / \mathrm{ml} / \mathrm{hr})\end{array}$ & $65.90 \pm 6.67$ & $65.60 \pm 6.67$ \\
\hline $\mathrm{t}^{1 / 2 \mathrm{a}}(\mathrm{hr})$ & $\begin{array}{l}2.00 \pm 0.20 \\
(2.60 \pm 0.08)^{*}\end{array}$ & $\begin{array}{l}2.20 \pm 0.20 \\
(2.45 \pm 0.08)^{*}\end{array}$ \\
\hline $\mathrm{K}_{\mathrm{a}}\left(\mathrm{hr}^{-1}\right)$ & $\begin{array}{l}0.35 \pm 0.03 \\
(0.27 \pm 0.01)^{*}\end{array}$ & $\begin{array}{l}0.32 \pm 0.03 \\
(0.28 \pm 0.01)^{*}\end{array}$ \\
\hline $\mathrm{K}_{\mathrm{el}}\left(\mathrm{hr}^{-1}\right)$ & $\begin{array}{l}0.21 \pm 0.01 \\
(0.21 \pm 0.01)^{*}\end{array}$ & $\begin{array}{l}0.20 \pm 0.01 \\
(0.23 \pm 0.01)\end{array}$ \\
\hline $\mathrm{t}_{1 / 2 \mathrm{el}}(\mathrm{hr})$ & $\begin{array}{l}3.30 \pm 0.20 \\
(3.25 \pm 0.13)^{*}\end{array}$ & $\begin{array}{l}3.50 \pm 0.20 \\
(3.00 \pm 0.13)^{*}\end{array}$ \\
\hline MAT (hr) & $\begin{array}{l}2.86 \pm 0.30 \\
(3.70 \pm 0.08)^{*}\end{array}$ & $\begin{array}{l}3.13 \pm 0.30 \\
(3.57 \pm 0.08)^{*}\end{array}$ \\
\hline $\mathrm{V}_{\mathrm{d}}(\mathrm{l} / \mathrm{hr})$ & $46.15 \pm 1.36$ & $44.44 \pm 1.36$ \\
\hline $\mathrm{Cl}(\mathrm{ml} / \mathrm{kg} / \mathrm{hr})$ & $9.69 \pm 0.72$ & $8.89 \pm 0.72$ \\
\hline
\end{tabular}

${ }^{*}$ saliva data are represented in parenthesis

read after 2 minutes against a urine blank at $445 \mathrm{~nm}$ in the spectrophotometer (UV-Visible SP6 Pye Unicam).

The same procedure was carried out for saliva samples and the absorbance read at $445 \mathrm{~nm}$ against saliva blank in the spectrophotometer (UV-Visible SP6 Pye Unicam). One millilitre Ehrlich's reagent was added to one millilitre of plasma. This was vortex mixed and a one in ten dilution of the resultant turbid solution was read against the plasma blank at $445 \mathrm{~nm}$ in a spectrophotometer. Calibration curve for Beer's plot was obtained using INH concentration of $12,6,3,1.5,0.75 \mathrm{mcg} / \mathrm{ml}$.

\section{Pharmacokinetic analysis}

To analyze the INH concentration data we assumed a one compartment open model with linear kinetics. The concentration-time data for each study period 1$24 \mathrm{~h}$ after completion of rifampicin administration were fitted by a non-linear least squares regression to the following equation, $\mathrm{C}=\mathrm{C}_{0} \cdot \mathrm{e}^{-(\mathrm{kt})}$ where $\mathrm{C}$ is the concentration at time $\mathrm{t}$ and $\mathrm{C}_{0}$ is the concentration when $t=0$. The elimination half life $\left(t_{1 / 2}\right)$ was calculated from the elimination rate constant $(\mathrm{K})$ by the formula $0.693 / \mathrm{K}$. The area under the serum concentration time curve (AUC) was calculated
Table 2. Urine INH pharmacokinetics parameter with or without OXC.

\begin{tabular}{lcc}
\hline Parameter (units) & Without OXC & With OXC \\
\hline $\begin{array}{l}\text { Total amount of drug excreted in } \\
\text { urine }(\mathrm{mg})\end{array}$ & $234.00 \pm 9.90$ & $253.70 \pm 9.90$ \\
$\begin{array}{l}\text { Percentage of oral dose excreted } \\
\text { in urine }(\%)\end{array}$ & $78.00 \pm 3.30$ & $84.60 \pm 3.30$ \\
Half life $(\mathrm{t} / \mathrm{s})(\mathrm{h})$ & $4.00 \pm 0.20$ & $3.80 \pm 0.20$ \\
Elimination constant $\left(\mathrm{kel}_{\mathrm{el}}\right)\left(\mathrm{h}^{-1}\right)$ & $0.17 \pm 0.01$ & $0.18 \pm 0.01$ \\
Renal clearance $(\mathrm{l} / \mathrm{h})$ & $7.85 \pm 0.32$ & $8.00 \pm 0.32$ \\
\hline
\end{tabular}

from 0 to $24 \mathrm{~h}$ by the trapezoidal rule and was extrapolated to infinity by adding the INH concentration at $24 \mathrm{~h}$ divided by K (Wagner, 1975). The volume of distribution $\left(\mathrm{V}_{\mathrm{d}}\right)$ was calculated for each treatment by dividing the dose of INH by the initial serum concentration of INH when $t$ is equal to zero. The total body clearance $(\mathrm{Cl})$ with or without administration of ofloxacin was obtained by multiplying $\mathrm{V}_{\mathrm{d}}$ by the quantity 0.693 divided by the serum half-life $(\mathrm{Vd} \times 0.693 / \mathrm{K})$ (Gibaldi and Perrie, 1975) . Renal clearance $\left(\mathrm{Cl}_{\mathrm{r}}\right)$ of $\mathrm{INH}$ was calculated by dividing the amount of INH recovered in urine by the AUC for serum concentrations versus time from $12-24 h$. The method of residuals was used to determine the absorption rate $\left(\mathrm{K}_{\mathrm{a}}\right)$, while the concentration maximum $\left(\mathrm{C}_{\max }\right)$ and the corresponding time $\left(\mathrm{T}_{\max }\right)$ were read off from the serum concentration versus time curve. The mean absorption time (MAT) was calculated from the reciprocal of $K_{a}\left(1 / K_{a}\right)$. The amount of INH excreted or recovered in urine was calculated using the method of Ritschel (Ritschel 1980). The saliva/plasma concentration ratio was calculated using the mean AUC's as described by Eatman et al., (1977) (Mean saliva AUC/Mean plasma AUC).

\section{Statistical analysis}

The differences between two related samples were analyzed using Student's t-test (paired). Differences were considered statistically significant at $p \leq 0.05$ (two tailed). Data are expressed as mean \pm SD.

\section{RESULTS}

The amount of plasma INH absorbed (AUC) was non-significantly reduced from $65.50 \mathrm{mcg} / \mathrm{ml} / \mathrm{h}$ (INH alone) to $59.60 \mathrm{mcg} / \mathrm{ml} / \mathrm{h}(\mathrm{INH}+\mathrm{OXC})$ but significantly increased in saliva data 8.96 (INH alone) and $9.35 \mathrm{mcg}$ in INH + OXC (Table1). The plasma $\mathrm{C}_{\max }$ of 


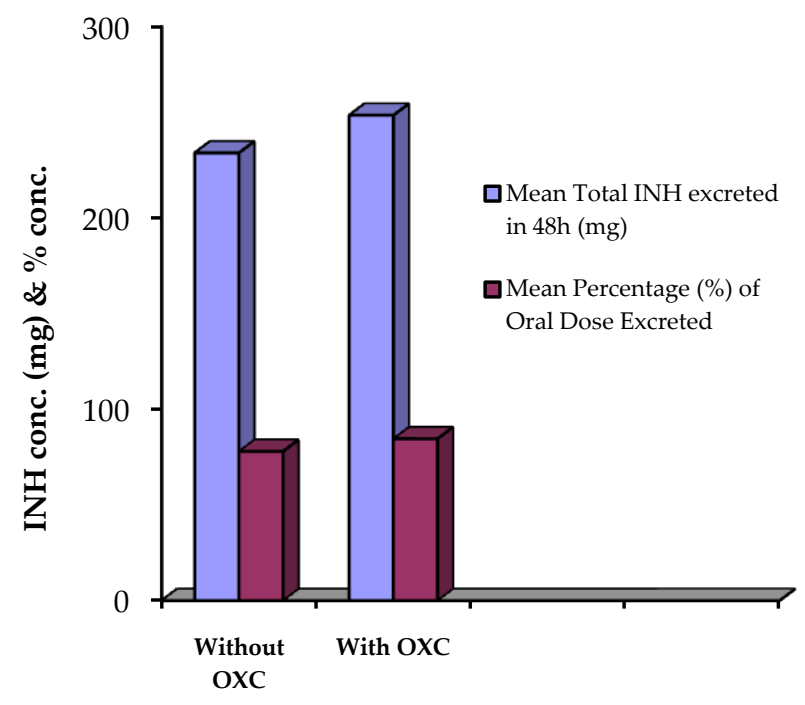

Figure 1. Mean total amount of INH excreted in Urine over $48 \mathrm{~h}(\mathrm{mg})$ and the percentage $(\%)$ of oral dose of INH excreted in urine with or without OXC.

INH with and without OXC was 4.7 and $4.5 \mathrm{mcg} / \mathrm{ml}$ respectively (Table 1) while the saliva $\mathrm{C}_{\max }$ of INH with and without OXC was 1.9 and $1.7 \mathrm{mcg} / \mathrm{ml}$ respectively. The plasma $\mathrm{T}_{\max }$ of $\mathrm{INH}$ with or without OXC significantly increased (2.0 and $1.5 \mathrm{~h}$ ) whereas the saliva $\mathrm{T}_{\max }$ of INH with or without OXC was not affected (3.0/3.0h). Absorption half-life with or without OXC range between 2.0 to $2.2 \mathrm{~h}$ in plasma and 2.45 to $2.60 \mathrm{~h}$ in saliva sample. There was a significant increased in Plasma INH $t_{1 / 2 e l}$ with OXC (3.50h) when compared with the plasma $\mathrm{t}_{1 / 2 \mathrm{l}}$ in INH alone $(3.30 \mathrm{~h})$ whereas a significant decrease was observed in saliva INH t/2el with OXC (3.00h) compared with saliva $t / 2$ el in INH alone (3.25h) (Table 1).The minimum absorption time (MAT) of INH in plasma showed a significant increase with OXC while in saliva, the MAT of INH decreased nonsignificantly with OXC (Table 1).

The mean cumulative amount of INH excreted increase significantly with OXC compared with INH alone. The elimination rate constant $\left(\mathrm{K}_{\mathrm{el}}\right)$ and $\mathrm{t} / 2$ based on urinary data shows slight increased in $\mathrm{Kel}_{\mathrm{el}}$ of INH in the presence of $\mathrm{OXC}$, t/2el values were $3.8 \mathrm{~h}$ with ofloxacin and $4.0 \mathrm{~h}$ without. There was a non significant increase in renal clearance with OXC (Table 2).

The mean amount and percentage of INH excreted with or without OXC are presented as bar chart in Figure 1, also presented as bar chart is the plasma

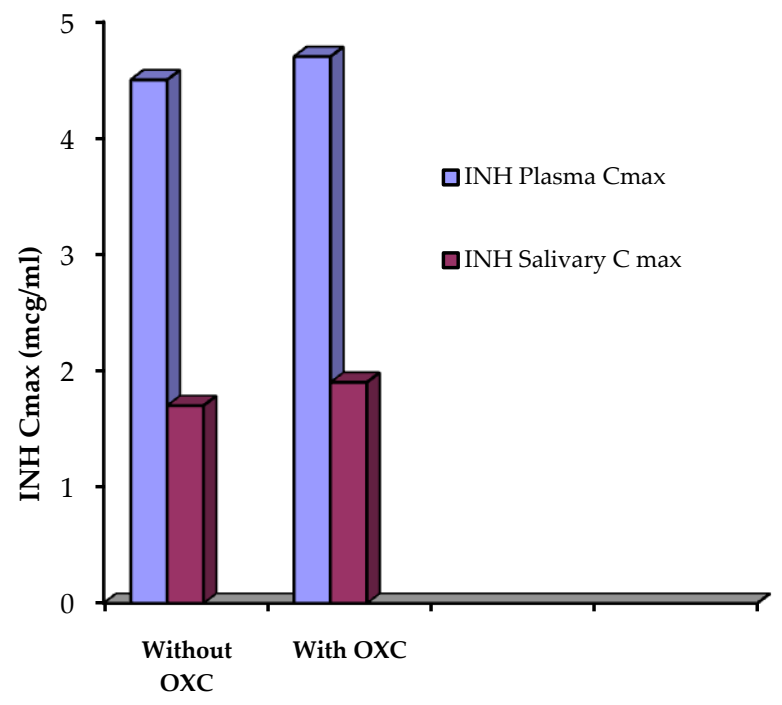

Figure 2. Plasma and Saliva INH $\mathrm{C}_{\max }(\mathrm{mcg} / \mathrm{ml})$ with or without OXC.

and saliva $\mathrm{C}_{\max }$ with or without OXC (Figure 2). Mean INH concentrations $(\mathrm{mcg} / \mathrm{ml})$ time curves in both plasma and saliva with and without OXC are shown in figure 3. From the figure, the peak INH concentration $\left(\mathrm{C}_{\max }\right)$ occurred at $1.5 \mathrm{~h}$, while the presence of OXC shifted the $\mathrm{T}_{\max }$ to $2 \mathrm{~h}$. Measurable INH concentration was obtained up to the $12^{\text {th }}$ hour. The figure indicates a non-significant effect of OXC on plasma and saliva curve of INH. The concentrations of INH in saliva were much lower than those in plasma as evidenced from Figure 3.

Figure 4 shows the graph of the cumulative INH excreted in the Urine versus time with and without OXC, the excretion was almost same within the first 7 hours, after which the excretion assumed almost a plateau with OXC causing more excretion of INH than the control. It is evident that the rate of excretion of INH (excretion per hour) was almost the same with or without OXC as shown in Figure 5.

\section{DISCUSSION}

The effect of ofloxacin on the pharmacokinetics profile of INH after oral administration in man, has been investigated. INH has proved to be a valuable addition to the available anti-TB drugs with a MIC of $1.0 \mathrm{mg} / \mathrm{ml}$ against Mycobacterium tuberculosis. Although it is metabolized by acetylation, by the hepatic enzyme acetyl transferase, it is largely 


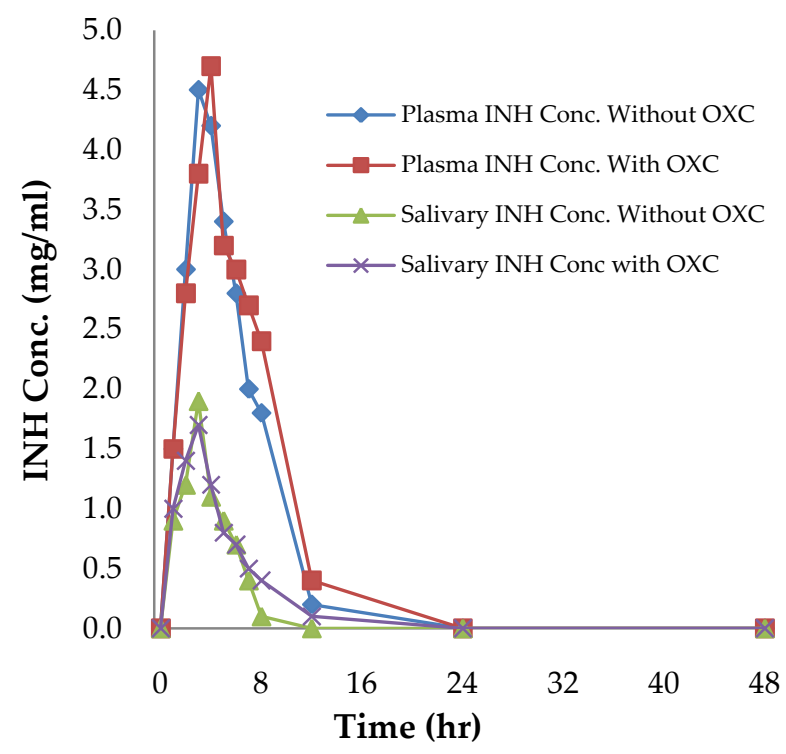

Figure 3. Mean Plasma and Saliva INH concentration with or without OXC.

excreted in urine. The rapidity of acetylation depends on the relative amount of acetyl transferase produced by the individual and it is genetically determined (Kazung 1982 ). In fast acetylators, the $t / 1 / 2$ of INH is $1-1.5 \mathrm{~h}$ whereas for slow acetylators, the $\mathrm{t} 1 / 2$ of INH is about 3h (Schild 1980). The established $\mathrm{T}_{\max }$ of $\mathrm{INH}$ is $1-2 \mathrm{~h}$ and the plasma $\mathrm{C}_{\max }$ is 3$5 \mathrm{mcg} / \mathrm{ml}$ (Schild, 1980; Jain, 1998).

The results of this study show that ofloxacin increased the rate of absorption (both $\mathrm{T}_{\max }$ and $\mathrm{C}_{\max }$ ) of INH but reduced the extent of absorption (AUC). In an earlier study on the effect of ciprofloxacin, another fluoroquinolones, on INH, the presence of ciprofloxacin led to an increase in the amount of INH absorbed but caused a slight reduction in the $\mathrm{C}_{\max }$ of INH (Ofoefule et al., 2001 ). This is attributed to the fact that ciprofloxacin as reported earlier is an inhibitor of cholinergic neurotransmission leading to an inhibition of gastric motility and emptying (Tamaoki, 1995). This may also be attributed to the fact that, all fluoroquinolones preparations may not exhibit exactly the same pharmacokinetic behavior owing to differences in their formulation additives and the manufacturers involved in the production of the various tablets.

When isoniazid was administered in combination with ofloxacin, there were little or no variations in the pharmacokinetic parameters calculated based on

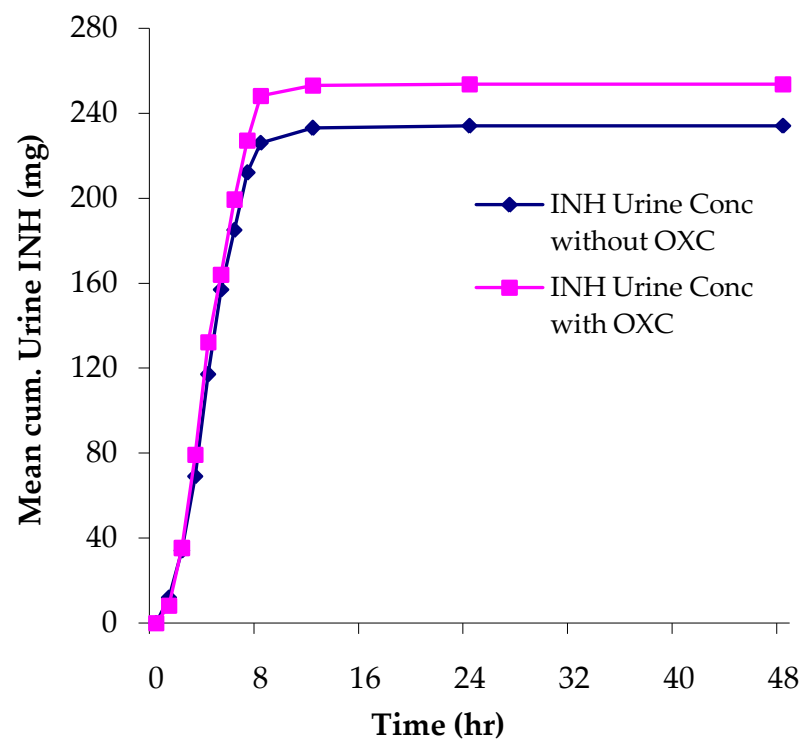

Figure 4. Mean Cumulative INH Excretion in Urine (mg) Versus Time (hr) with or without OXC.

the salivary and plasma estimates. This could be due to the small sample size in this group $(n=5)$ and inter-individual differences in the absorption and metabolism of the drug. Ofloxacin reduced the volume of distribution of INH, this variation in $\mathrm{Vd}_{\mathrm{d}}$ of INH owing to the co-administration of ofloxacin with INH is of doubtful clinical significance being statistically insignificant. Ofloxacin increased the urinary excretion of INH compared to the control which may be due to its increase in the absorption rate and the overall bioavailability of $\mathrm{INH}$, it could be that the higher level of INH in the blood made for the greater excretion of INH in the urine. It has been reported earlier that other fluoroquinolones also increase the urinary excretion of INH (Orisakwe et al., 2004). The mean INH excretion in urine versus time graphs assumed the form of a plateau in each phase with ofloxacin giving higher values than the control. The excretion profile of INH was almost same in the two phases signifying that ofloxacin does not affect the rate of INH plasma excretion.

From the saliva data, ofloxacin increased the rate of absorption of INH. This is in harmony with the conclusion drawn from the plasma data that INH $\mathrm{C}_{\max }$ and AUC in saliva were less than what were obtained in plasma in the two phases. This scenario also conforms to the findings obtained for some other drugs by other researchers (Kumar and Gurumurthy, 2004). Using saliva instead of blood 


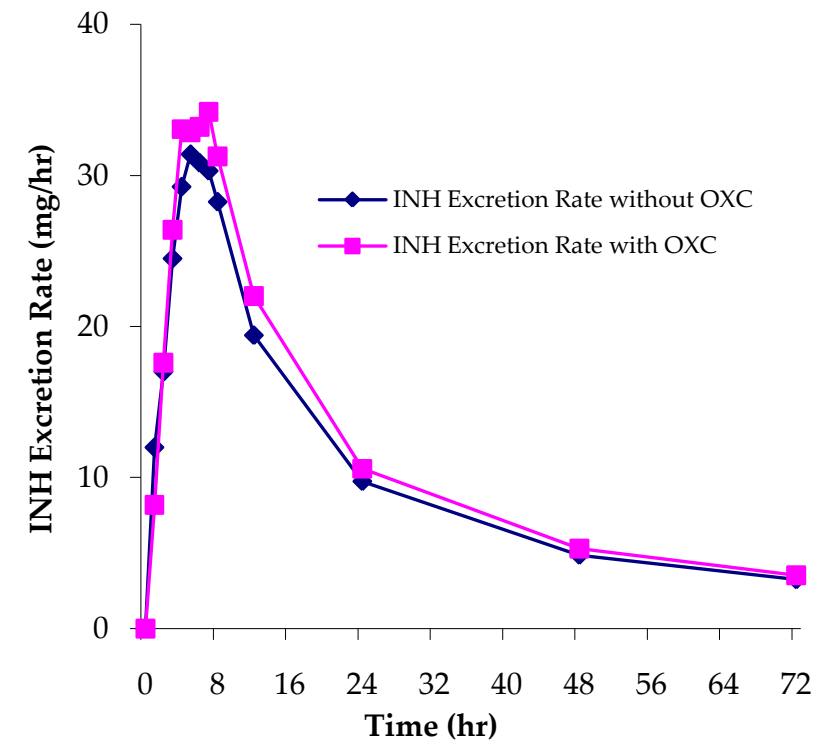

Figure 5. Excretion rate of INH with or without OXC.

for pharmacokinetic investigations has obvious practical advantages. It is a painless, non-invasive procedure, hence suitable for the collection of multiple specimens. Variable results have been reported for the ratio of saliva to serum concentrations. Koizumi et al. (1994) reported a ratio of 1.0 between 2-8 $\mathrm{h}$ after administration of a $300 \mathrm{mg}$ dose. Fujita et al. (1995) in their studies on patients with renal impairment had reported a ratio of 1:1 for saliva to serum concentrations. However, Warlich et al. (1990) have reported a ratio of 0.6 and a close relation of levels in the saliva and serum $(r=0.99)$, which is consistent with our findings. The mean saliva/plasma $(\mathrm{S} / \mathrm{P})$ ratio of ofloxacin was around 0.6 and this remained the same when ofloxacin was given in any combination. From this study, the mean saliva plasma concentration ratio using the mean AUC's as described by Eatman et al. (1977) gave the mean INH saliva plasma ratio of 0.14 in control and 0.16 with ofloxacin. The $\mathrm{S} / \mathrm{P}$ ratio is a possible measure of the amount of protein binding to the drug. There was a good correlation (0.94) with respect to drug concentrations. The pharmacokinetic parameters such as $C_{\max }, t_{\max }, \mathrm{AUC}$, and $\mathrm{t}_{1 / 2}$ of isoniazid did not change when given in combination with other anti-TB drugs suggesting that the pharmacokinetics of isoniazid are not affected or altered when administered with the other anti-TB drugs, however, synergistic or additive effect may be seen when used in multiple drug therapy. There was no $\mathrm{pH}$ alteration observed in both urine and saliva sample from $\mathrm{pH}$ determination both at the collection and just before the analysis.

\section{CONCLUSION}

The present study shows that several pharmacokinetic parameters can be calculated using salivary concentrations of INH as can be done with plasma. The estimation of INH levels in saliva seems to be useful in therapeutic drug monitoring and pharmacokinetic studies. Based on the salivary levels, the present study compares the pharmacokinetic parameters of isoniazid when given alone and in combination with ofloxacin.

Further investigations are required to determine whether the concentration of isoniazid in saliva can act as a valid index after multiple dosing.

\section{REFERENCES}

Bjornosjo, KB. and Jarnuff, B. (1967) Determination of isonicotinic acid . hydrazide in blood serum. scand-j-clinlab-invest; 20:39-40.

Diver, J. (1998) The mode of action of the 4-Quinolones: as update Quinolones bulletin. Reports on gyrase inhibitors; Vol 4 No 2: pp25-28.

Dorthe SA, Torgny W, Martin D. (1995) Hepatotoxicity caused by the combined action of isoniazid and rifampicin. Thorax,; 50:213-214.

Drobitch RK, Svensson CK. (1992) Therapeutic drug monitoring in saliva: An update.Clin Pharmacokinet; 23:365-79.

Eatman, FB., Maggio AC., Pocelinko, HG., et al., (1977) Blood and salivary concentration of sulfamethoxazole and trimethoprim in man . J of Pharmacokinetics and Biopharmaceutics ; vol. 5(6); 615-624.

EMEA/CVMP/SAGAM/184651/2005- Consultation. London, 18 January 2006.

Fujita K, Matsuoka N, Takenaka I. (1995) Pharmacokinetics of ofloxacin-measurement of drug concentrations in saliva of patients with impaired renal function. Drugs;49:312-3.

Gautam VP (2009) Treatment of leprosy in India. Journal of Postgraduate Medicine; 55, 220-224.

Gibaldi, M. and Perrie, D. (1975) Pharmacokinetics. New York: Marcel Decker.

Goel Atul, Goel Alka and Uma N (1998) Using the newer quinolones. A Judicious Approach, MEDIQUEST: A Ranbaxy publication; vol 16 No 2 pp. 8-11, 14-18. 
Guay, DR. (1992a ) The role of the fluoroquinolones. Pharmacotherapy; 12(6): 571-585.

Guay DR. (1992b) The role of the fluoroquinolones. Pharmacotherapy; 7:71-85.

Jain, NK. (1998) Management of Multi-Drug Resistant Tuberculosis. MEDIQUEST Ranbaxy Publication; 16(2):1-7.

Kazung, BG. (1982) Basic and Clinical pharmacology. Lange publishers. Los Altos; Pp1-7.

Koizumi F, Ohnishi A, Takemura H, Okubo S, Kagami T, Tanaka T. (1994) Effective monitoring of concentrations of ofloxacin in saliva of patients with chronic respiratorytract infections. Antimicrob Agents Chemother; 38:1140-3.

Kumar. A.K.H, Gurumurthy, P. (2004). Ofloxacin pharmacokinetics in saliva. Indian J Pharmacol, 36(2): 80-83.

Maninder SS, Santosh SS, Hemangi RJ, Jean-Francois B. (2011) Is there a role for rifampicin, ofloxacin and minocycline (ROM) therapy in the treatment of leprosy? Systematic review and meta-analysis, Tropical Medicine and International Health; 16(12): 1541-1551.

Meima A, Smith WC, van Oortmarssen GJ, Richardus JH, Habbema JD. (2004) The future incidence of leprosy: a scenario analysis. Bulletin of the World Health Organization; 82, 373-380.

Mucklow JC.(1982) The use of therapeutic drug monitoring. Ther Drug Monit,; 4:229-47.

O'Brien DP, McDonald A, Callan P, Robson M, Friedman ND, Hughes A, Holten I, Walton A and Athan E. (2012) Successful Outcomes with Oral Fluoroquinolones Combined with Rifampicin in the Treatment of Mycobacterium ulcerans: An Observational Cohort Study. PLoS Negl Trop Dis; 6(1): e1473. [DOI]

Ofoefule SI, Obodo CE, Orisakwe OE, Afonne OJ, Ilondu NA, Maduka SO,Anusiem CA, Agbasi PU. (2001) Some Plasma Pharmacokinetics Parameters of Isoniazide (INH) in the presence of a Fluoroquinolones Anti-bacterial agent. American Journal of Therapeutics; 8 (4): 243-246.

Orisakwe OE, Agbasi PU, ofoefule SI, Ilondu NA, Afonne OJ., Anusiem CA., Ilo EC., Maduka SO. (2004) Effect of Perfloxacin on urinary excretion of Rifampicin. American Journal of Therapeutics 11(1); 13-16.

Ritschel, WA. (1980) Handbook of Basic Pharmacokinetics.2 ${ }^{\text {nd }}$ edn. Illinois: Hamilton;166.

Schild HO. (1980) Applied pharmacology. elbs \& churchill living stone. london; 34-49.

Sehgal VN, Sardana K, Dogra S. (2008) The imperatives of leprosy treatment in the pre-and post-global leprosy elimination era: appraisal of changing the scenario to current status. The Journal of Dermatological Treatment;19, 82-91.

Spectar R, Park GD, Johnson GF, Vesell ES. (1988). Therapeutic drug monitoring. Clin Pharmacol Ther;43:345-53.
Tamaoki, J., Tagaya, E., Chiyotani, A. et al (1995) Effect of ciprofloxacin on cholinergic neuro-effector transmission in airway smooth muscle. Drugs (supplement); 49: 298-300.

Visschedijk J, van de Broek J, Eggens H, Lever P, van Beers S, Klatser P (2000) Mycobacterium leprae - millennium resistant!Leprosy control on the threshold of a new era. Tropical Medicine and International Health; 5, 388-399.

Wagner, JG. (1975). Fundamentals of clinical pharmacokinetics. Hamilton: Drug Intelligence Publication III:63

Walker, R. et al., (1991). The Fluoroquinolones. Mayo Clin. Proc.; 66: 1249-1259.

Warlich R, Korting HC, Schafer-Korting M, Mutschler E. (1990). Multiple-dose pharmacokinetics of ofloxacin in serum, saliva and skin blisterfluid of healthy volunteers. Antimicrob Agents Chemother, 34:78-81.

Wolfson J. and Hooper D. (1991a). Overview of fluoroquinolones safety. Amer. J. Med; 9(suppl 6A): S153-S161.

World Health Organization Chemotherapy of Leprosy for Control Programmes (No. 675). World Health Organization 1982.

World Health Organization WHO Expert Committee on Leprosy. World Health Organization, Geneva 1998a.

World Health Organization Global leprosy situation. Weekly epidemiological record 2010a. [LINK] (accessed $2^{\text {nd }}$ May 2012).

World Health Organization. WHO model prescribing information; drugs used in leprosy. World Health Organization, Geneva 1998b. 